\title{
Absorption of fat-soluble vitamins and sterols
}

\author{
GILBERT R. THOMPSON \\ From the Department of Medicine, Royal Postgraduate Medical School, London
}

The molecular structure of the four fat-soluble vitamins and of cholesterol, the major intestinal sterol in man, are shown in Figure 1. In spite of the obvious dissimilarities that exist between these compounds they possess one common feature, namely, they are all nonpolar lipids with extremely low solubilities in aqueous media. Because of this, it is convenient to consider them together when examining the mechanisms involved in their absorption, although the individual differences that exist will also be discussed.

\section{Mechanisms of Absorption}

INTRALUMINAL OR UPTAKE PHASE

The importance of bile salts in the absorption of fatsoluble vitamins has been known for many years, although it was only relatively recently that the mechanism of this effect was elucidated. Borgström in 1960 re-emphasized that during fat absorption the intestinal contents could be separated by ultracentrifugation into a supernatant oil phase and an infranatant aqueous, or micellar, phase. Subsequently, Hofmann and Borgström (1962) showed that the micellar phase consisted of aggregates, $5 \mathrm{~m} \mu$ in diameter, of monoglycerides, ionized fatty acids and bile salts, termed mixed micelles whereas the oil phase consisted mainly of unhydrolysed triglyceride in the form of emulsion particles, $1,000 \mathrm{~m} \mu$ in diameter. Nonpolar lipids such as cholesterol and the fat-soluble vitamins partition themselves between the oil and micellar phases (Borgström, 1967). There is some evidence that polar lipids, such as fatty acids, can be absorbed reasonably well from emul-<smiles>CC(C)CCCC(C)C1CCC2C3CC=C4CC(O)CCC4(C)C3CCC12C</smiles>

CHOLESTEROL<smiles>Cc1c(C)c2c(c(C)c1O)CCC(C)(CCCC(C)CCCC(C)CCCC(C)C)O2</smiles>

Fig. 1.<smiles>C=C1CCC(O)C/C1=C/C=C1/CCCC2C1CCC2C(C)CCCC(C)C</smiles><smiles>CC(=CCC1C(=O)c2ccccc2C(=O)C1C)CCCC(C)CCCC(C)CCCC(C)C</smiles>

VITAMIN $K_{1}$ (Phylloquinone) 
sions and that incorporation into mixed micelles is not necessarily a prerequisite for their absorption (Simmonds, Redgrave, and Willix, 1968). However, in view of the important role of bile salts in the absorption of nonpolar lipids, it seems likely that in their case, micelle formation is essential. Evidence in favour of this, and which demonstrates the contrast between polar and nonpolar lipids, can be found in a recent study where the absorption of oleic acid and $\alpha$-tocopherol was compared in lymph-fistula rats (MacMahon and Thompson, 1970). The results showed that the ratio between the percentage absorption of $a$-tocopherol and oleic acid from a mixed micellar solution was strikingly lowered if these lipids were instead administered in an emulsion (Fig. 2).

Apart from micelle formation, another important intraluminal event is that hydrolysis of cholesterol and fat-soluble vitamin esters must occur before

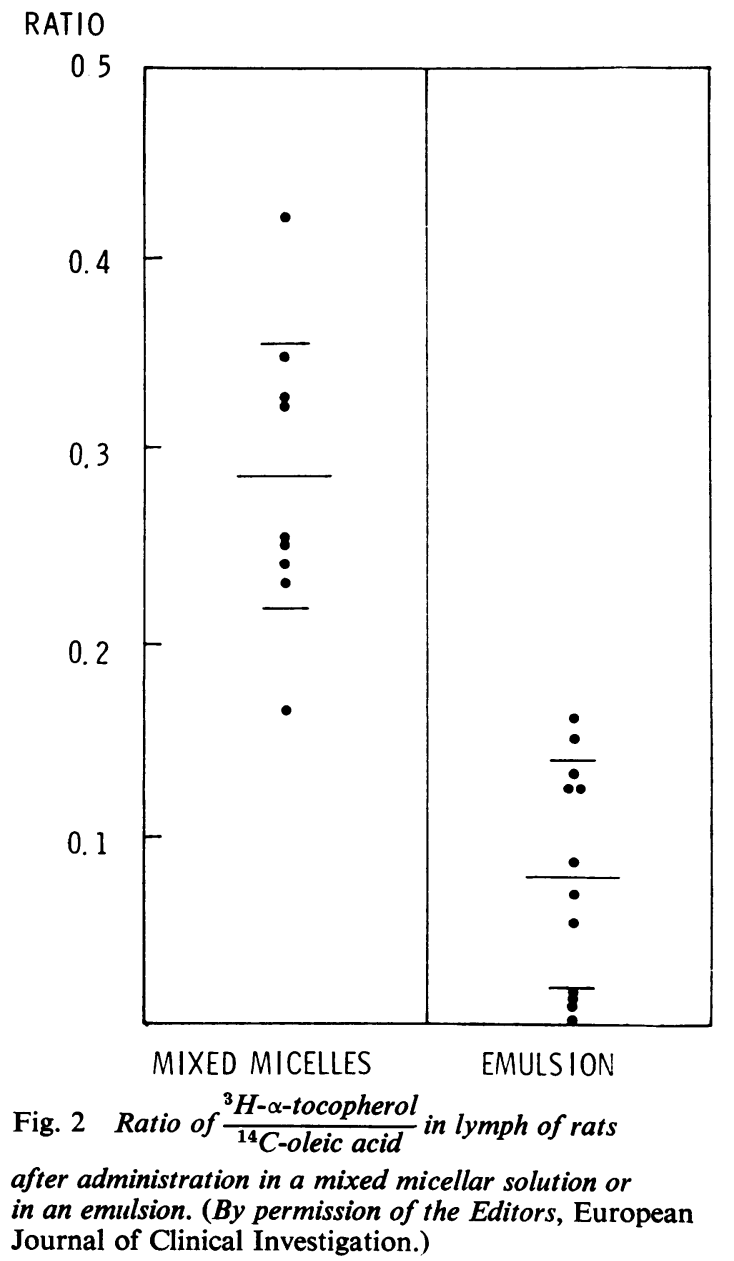

absorption can take place. The enzymes involved in the hydrolysis of vitamin A esters have been studied in considerable detail by Ganguly (1969), who has proposed the existence of both a pancreatic and an intestinal brush border esterase. This also seems to be so in the case of cholesterol, although since both free and esterified cholesterol are present in mixed micelles, the reason why unhydrolysed esters fail to be absorbed is unclear (Treadwell and Vahouny, 1968). Nor is the mechanism whereby free cholesterol and fat-soluble vitamins are transferred from the interior of micelles to the absorptive cell completely understood, although it is probable that this involves direct contact between micelles and the cell surface followed by diffusion of their constituent lipids into the brush border membrane (Simmonds, Hofmann, and Theodor, 1967). There is some evidence that vitamin $\mathbf{D}$ absorption is indeed mediated by a non-saturable diffusion mechanism (Schacter, Finkelstein, and Kowarski, 1964).

The actual site of uptake of nonpolar lipids within the small intestine appears to be similar to that of dietary triglyceride. Borgström (1960) has shown in the human subject that cholesterol is absorbed chiefly in the proximal jejunum, and absorption of the fatsoluble vitamins also appears to take place in this region (Booth, 1968).

INTRACELLULAR PHASE

The chief differences in the absorption of cholestero and the various fat-soluble vitamins occur during the intracellular phase of their absorption. However, they all have one feature in common, namely, that their rate of uptake into the mucosa is very much more rapid than their subsequent transport through the cell. This has been well demonstrated in the case of vitamin D, for example, by Schacter et al (1964).

\section{Cholesterol}

Following its uptake as the free sterol, cholesterol is largely re-esterified during its passage through the intestinal mucosa. Approximately two thirds of the absorbed sterol undergoes esterification by an esterase or esterases which appear to be partly of mucosal and partly of pancreatic origin and require bile salts as a cofactor (Treadwell and Vahouny, 1968). Within the small intestine cholesterol is esterified preferentially with oleic acid (Karmen, Whyte, and Goodman, 1963).

\section{Vitamin A}

Vitamin A or retinol is like cholesterol, also largely re-esterified during absorption, although in this instance preferentially with palmitic acid (Fidge, Shiratori, Ganguly, and Goodman, 1968). A major dietary source of vitamin $A$ is the pro-vitamin, $\beta$ carotene. It appears that after uptake into the 
intestinal mucosa, each molecule of $\beta$-carotene is split into two molecules of retinal. Retinal, an aldehyde, then undergoes reduction to retinol which is subsequently converted into retinyl esters (Goodman, 1969). Studies in human subjects have shown that only $20-30 \%$ of $\beta$-carotene is absorbed unchanged, the remainder being metabolized as discussed above (Goodman, Blomstrand, Werner, Huang, and Shiratori, 1966).

\section{Vitamins $D, E$, and $K$}

These vitamins pass through the intestinal mucosa without any major modifications. A small proportion of vitamin D is esterified (Fraser and Kodicek, 1968), but never to the same extent as cholesterol or vitamin A. Both vitamins E (Johnson and Pover, 1962) and K (Blomstrand and Forsgren, 1968) are absorbed into lymph largely unchanged.

\section{TRANSPORT OR EXIT PHASE}

The major route of transport of cholesterol and the fat-soluble vitamins from the intestinal mucosa into blood is via the lymph. This has been demonstrated in numerous studies using lymph fistula rats and also in humans with cannulated thoracic ducts (Forsgren, 1969). The rate of exit of free cholesterol and vitamin $\mathrm{D}$ into lymph is increased by the simultaneous administration of exogenous triglyceride (Thompson, Ockner, and Isselbacher, 1969). Vitamin E absorption is affected in a similar manner (MacMahon, Neale, and Thompson, 1971) as shown in Figure 3. This enhancement of absorp- tion is probably related to the increased synthesis of chylomicrons that occurs during fat absorption, and on which cholesterol and the fat-soluble vitamins are largely transported in lymph. However, there is evidence in lymph fistula rats that during absorption of saturated fatty acids a significant proportion of absorbed cholesterol is carried on very low density lipoproteins (VLDL) of intestinal origin, whereas most of the cholesterol is in chylomicrons during absorption of unsaturated fatty acids (Ockner, Hughes, and Isselbacher, 1969). Thompson et al (1969) had previously found a higher ratio of free to esterified cholesterol in lymph during administration of unsaturated fatty acids than during the administration of saturated fatty acids, presumably because chylomicrons contain more free cholesterol, relative to esterified, than do very low density lipoprotein particles (Ockner et al, 1969).

Although intestinal lymph is undoubtedly the major pathway of absorption for cholesterol and the fat-soluble vitamins, it is probable that some absorption also occurs via the portal vein. Evidence for this has been put forward for vitamin A by Gagnon and Dawson (1968), for vitamin D (Pihl, Iber, and Linscheer, 1970), and, recently, for vitamin E (MacMahon et al, 1971). In the latter study, the evidence for portal absorption included finding higher concentrations of labelled $a$-tocopherol in portal venous than in aortic plasma. Furthermore, it was observed that small amounts of labelled free cholesterol also appeared to be absorbed via the portal vein. These findings may explain why small

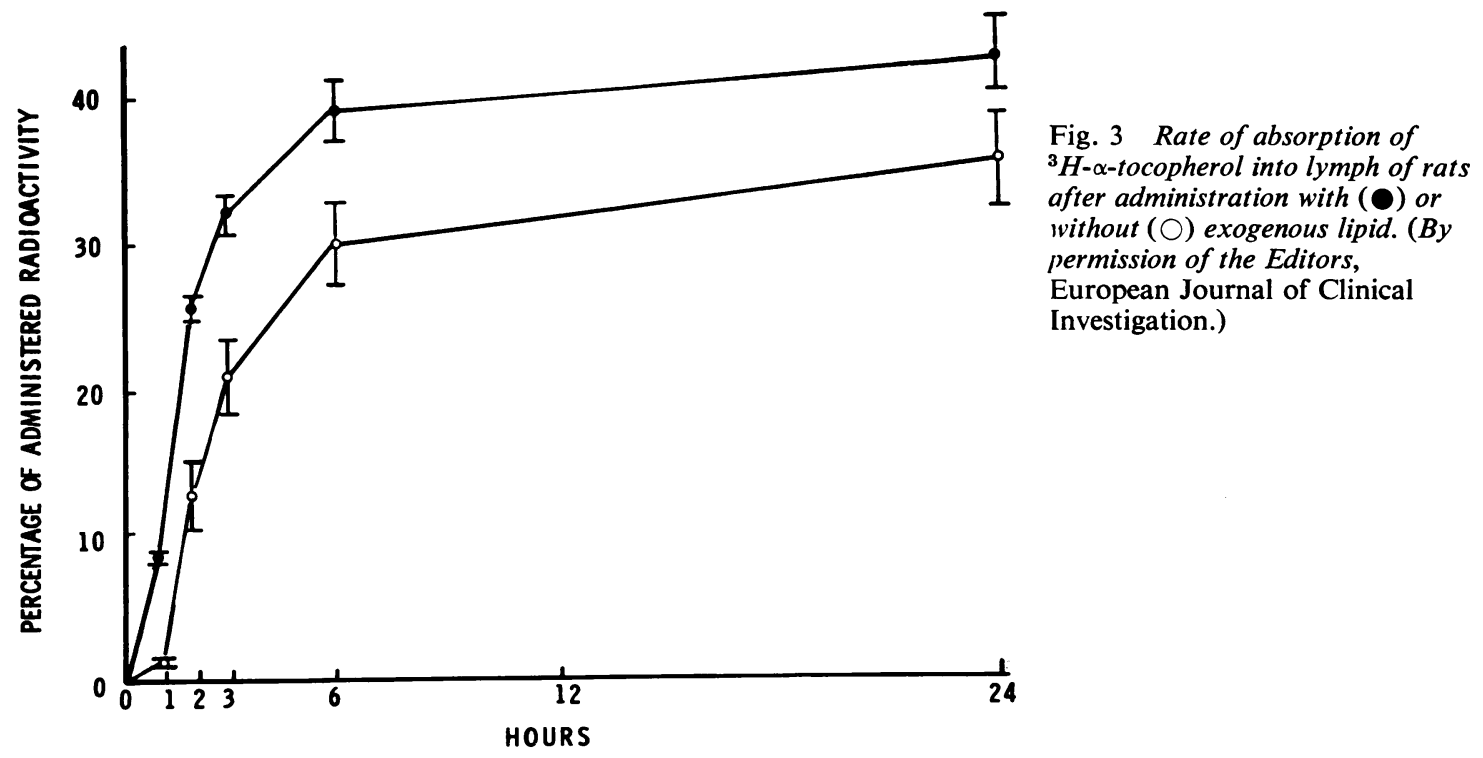


amounts of vitamin $E$ can be demonstrated in the blood of treated patients with $\alpha \beta$-lipoproteinaemia, in whom lymphatic transport of lipids cannot occur (Muller and Harries, 1969).

\section{Measurement of Absorption}

The availability during the last 10 years of isotopically labelled fat-soluble vitamins has enabled the overall absorption of physiological doses of vitamin A (Goodman et al, 1966), D (Thompson, Lewis, and Booth, 1966a; Avioli, Lee, McDonald, Lund, and DeLuca, 1967), E (Kelleher and Losowsky, 1970; MacMahon, and Neale, 1970), and K (Shearer, Barkhan, and Webster, 1970) to be studied in man. In view of the possibility that some absorption of the fat-soluble vitamins may occur via the portal vein, it would seem that these studies, in which measurement of absorption was based on faecal excretion of radioactivity after an oral dose, are likely to give a more complete estimate of net absorption than those based on lymphatic recovery, quite apart from being much simpler. Taken as a group, the absorption of fat-soluble vitamins appears to be much less complete than that of dietary triglyceride, since approximately $50 \%$ of an administered dose is recoverable from the faeces during the subsequent five days, partly in the unchanged form. After an oral dose the appearance of fat-soluble vitamins in plasma tends to be slower than that of absorbed triglyceride, although during the early phase of their absorption they enter plasma mainly in association with chylomicrons.

Measurement of cholesterol absorption in man by similar techniques (Borgström, 1969) does not give a true picture of long-term net absorption, because of the very considerable enterohepatic re-circulation of cholesterol, and more complex methods appear to be necessary (Grundy and Ahrens, 1969).

\section{Causes of Malabsorption}

There are numerous case reports in the literature of patients with malabsorptive disorders developing clinical syndromes due to deficiency of vitamins D or $\mathbf{K}$ but less often of vitamins A or E, presumably because lack of the latter is relatively asymptomatic. However, Albright and Stewart (1940) recorded the simultaneous occurrence of overt deficiency of vitamins $A, D$, and $K$, and postulated the presence of subclinical vitamin $\mathrm{E}$ deficiency in a patient who had steatorrhoea. Biochemical evidence of vitamin E deficiency has been demonstrated quite frequently in patients with gastrointestinal disorders, although from the clinical aspect its significance is difficult to assess (MacMahon and Neale, 1970).
There are three major situations in which malabsorption of fat-soluble vitamins may occur.

\section{BILIARY OR PANCREATIC INSUFFICIENCY} In view of the importance of micelle formation for the absorption of nonpolar lipids it is not surprising $\frac{}{0}$ that severe malabsorption of labelled vitamins $A, D, \frac{\partial}{\bar{c}}$ $E$, and $K_{1}$ has been demonstrated in patients with $\vec{\nabla}$ biliary obstruction in whom cannulation of the $\varrho$ thoracic duct had been undertaken (Forsgren, 1969). The radioactivity recovered from the lymph of these $\overrightarrow{0}$ patients was in every instance less than $3 \%$ of the administered dose, whereas in control subjects 6-60\% $\vec{\omega}$ was recovered. Other studies, in which the faecal excretion of radioactivity was used as an index of ? absorption, showed marked malabsorption of both $ఓ$ labelled vitamins D (Thompson et al, 1966a) and E ú (MacMahon and Neale, 1970) in patients with $\vec{\infty}$ steatorrhoea of similar origin. The degree of mal- $c$

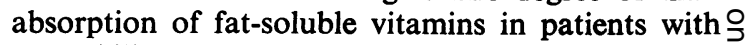
pure biliary obstruction is usually severe, even though the steatorrhoea may be relatively slight.

\section{MALABSORPTION OF GASTROINTESTINAL ORIGIN}

Fat-soluble vitamin deficiencies can occur after $\vec{\varphi}$ partial gastrectomy or small intestinal resectio However, vitamin D absorption is usually onf slightly subnormal in patients with postgastrectori steatorrhoea (Thompson, Lewis, and Booth, 1966 $) \overline{\text { }}$ ) and may even be normal, suggesting that dietary deficiency during the winter months is a more $\stackrel{\unrhd}{\stackrel{\perp}{\varrho}}$ important factor in causing the osteomalacia $\overrightarrow{\vec{\theta}}$ (Thompson, 1970). In contrast, patients with adult $\frac{0}{3}$ coeliac disease often show marked malabsorption of vitamin $\mathbf{D}$, whose severity is directly proportionalof to their degree of steatorrhoea (Thompson et al, 1966a). Studies on the absorption of vitamin $E$ in a? similar range of patients gave comparable findings $\frac{0}{5}$ and, in addition, demonstrated the presence of:marked malabsorption in two patients with intestinalo lymphangiectasia (MacMahon and Neale, 1970). Recently, malabsorption of vitamin $\mathrm{K}$ has also been웅 demonstrated in patients with various types of $>$ steatorrhoea (Shearer, Mallinson, Webster, and으․ Barkhan, 1970).

\section{IATROGENIC MALABSORPTION}

The insoluble anion exchange resin, cholestyramine, and the soluble polycationic antibiotic, neomycin 0 are both used therapeutically to lower the serumo

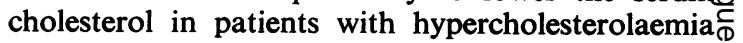
(Hashim and Van Itallie, 1965; Samuel, Holtzman,? and Goldstein, 1967). Cholestyramine acts by bind- $D$ ing bile acids within the small intestinal lumen, thus not only enhancing their excretion but also impair- 
ing micelle formation. Neomycin, in contrast, interacts chiefly with the fatty acid anions of mixed micelles, thus inducing precipitation of the entire micellar complex (Thompson, MacMahon, and Claes, 1970) and, presumably, impairing cholesterol absorption. Since these drugs interfere with micelle formation, it is not surprising that cholestyramine has also been shown to decrease the absorption of vitamins $\mathbf{A}$ and $\mathrm{K}$ (Whiteside, Harkins, Fluckiger, and Sarett, 1965) and also of vitamin D (Thompson and Thompson, 1969).

\section{References}

Albright, F., and Stewart, J. D. (1940). Hypovitaminosis of all fat soluble vitamins due to steatorrhoea. New Engl. J. Med., 223, 239-241.

Avioli, L. V., Lee, S. W., McDonald, J. E., Lund, J., and DeLuca, H. F. (1967). Metabolism of vitamin $D_{3}-{ }^{2} H$ in control subjects and patients with intestinal malabsorption. J. clin. Invest., 45, 94-102.

Blomstrand, R., and Forsgren, L. (1968). Vitamin $\mathrm{K}_{1}-{ }^{-3} \mathrm{H}$ in man. Its intestinal absorption and transport in the thoracic duct lymph. Int. Z. Vitamin-forsch., 38, 45-64.

Bosth, C. C. (1968). Effect of location along the small intestine on absorntion of nutrients. In Handbook of Physiology, section 6, vol. 3, pp. 1513-1528, edited by C. F. Code. American Physiological Society, Washington DC.

Borgström, B. (1960). Studies on intestinal cholesterol absorption in the human. J. clin. Invest., 39, 809-313.

Borgström, B. (1967). Partition of lipids between emulsified oil and micellar phases of glyceride-bile salt dispersions. J. Lipid Res., 8, 598-608.

Borgström, B. (1969). Quantification of cholesterol absorption in man by fecal analysis after the feeding of a single isotope-labeled meal. J. Lipid Res., 10, 331-337.

Fidge, N. H., Shiratori, T., Ganguly, J., and Goodman, D. S. (1968). Pathways of absorption of retinal and retinoic acid in the rat. J. Lipid Res., 9, 103-109.

Forsgren, L. (1969). Studies on the intestinal absorption of labelled fat-soluble vitamins (A, D, E and K) via the thoracic-duct lymph in the absenze of bile in man. Acta chir. scand., Suppl. 399, 5-29.

Fraser, D. R., and Kodizek, E. (1968). Investigations on vitamin D esters synthesized in rats. Turnover and sites of synthesis. Biochem. J., 106, 491-496.

Gagnon, M., and Dawson, A. M. (1968). Effect of bile on vitamin A absorption in the rat. Proc. Soc. Exp. biol. (N.Y.), 127, 99-102.

Ganguly, J. (1969). Absorption of vitamin A. Amer. J. clin. Nutr., 22, 923-933.

Goodman, D. S. (1969). Biosynthesis of vitamin A from beta-carotene. Amer. J. clin. Nutr., 22, 963-965.

Goodman, D. S., Blomstrand, R., Werner, B., Huang, H. S., and Shiratori, T. (1966). The intestinal absorption and metabolism of vitamin $A$ and beta-carotene in man. J. clin. Invest., 45, 1615-1623.

Grundy, S. M., and Ahrens, E. H. (1969). Measurements of cholesterol turnover, synthesis and absorption in man, carried out by isotopic kinetic and sterol balance methods. J. Lipid Res., 10, 91-107.

Hashim, S. A., and Van Itallie, T. B. (1965). Cholestyramine resin therapy for hypercholesteremia. J. Amer. med. Ass., 192, 289293.

Hofmann, A. F., and Borgström, B. (1962). Physico-chemical state of lipids in intestinal content during their digestion and absorption. Fed. Proc., 21, 43-50.
Johnson, P., and Pover, W. F. R. (1962). Intestinal absorption of $\alpha$-tocopherol. Life Sci., 14, 115-117.

Karmen, A., Whyte, M., and Goodman, D. S. (1963). Fatty acid esterification and chylomicron formation during fat absorption. I Triglycerides and cholesterol esters. J. Lipid Res., 4, 312-321.

Kelleher, J., and Losowsky, M. S. (1970). The absorption of $\alpha-$ tocopherol in man. Brit. J. Nutr., 24, 1033-1047.

MacMahon, M. T., and Neale, G. (1970). The absorption of $\alpha$-tocopherol in control subjects and in patients with intestinal malabsorption. Clin. Sci., 38, 197-210.

MacMahon, M. T., and Thompson, G. R. (1970). Comparison of the absorption of a polar lipid, oleic acid, and a non-polar lipid, $\alpha$-tocopherol from mixed micellar solutions and emulsions. Europ. J. clin. Invest., 1, 161-166.

MacMahon, M. T., Neale, G., and Thompson, G. R. (1971). Lymphatic and portal venous transport of $\alpha$-tocopherol and cholesterol. Europ. J. clin. Invest. 1, 288.

Muller, D. P. R., and Harries, J. T. (1969). Vitamin E studies in children with malabsorption. Biochem. J., 112, 28P.

Ockner, R. K., Hughes, F. B., and Isselbacher, K. J. (1969). Very low density lipoproteins in intestinal lymph: role in triglyceride and cholesterol transport during fat absorption. J. clin. Invest., 48, 2367-2373.

Pihl, O., Iber, F. L., and Linscheer, W. G. (1970). The enhancement of vitamin $\mathrm{D}_{3}$ absorption in man by medium and long chain fatty acids. (Abstr.) Clin. Res., 18, 462.

Samuel, P., Holtzman, C. M., and Goldstein, J. (1967). Long-term reduction of serum cholesterol levels of patients with atherosclerosis by small doses of neomycin. Circulation, 35, 938-945.

Sshazter, D., Finkelstein, J. D., and Kowarski, S. (1964). Metabolism of vitamin D. I. Preparation of radioactive vitamin D and its intestinal absorption in the rat. J. clin. Invest., 43, 787-796.

Shearer, M. J., Barkhan, P., and Webster, G. R. (1970). Absorption and excretion of an oral duse of tritiated vitamin $K_{1}$ in man. Brit. J. Haemat., 18, 297-308.

Shearer, M. J., Mallinson, C. N., Webster, G. R., and Barkhan, P. (1970). Absorption of tritiated vitamin $K_{1}$ in patients with fat malabsorption. (Abstr.) Gut, 11, 1063-1064.

Simmonds, W. J., Hofmann, A. F., and Theodor, E. (1967). Absorption of cholesterol from a micellar solution: Intestinal perfusion studies in man. J. clin. Invest., 46, 874-890.

Simmonds, W. J., Redgrave, T. G., and Willix, R. L. S. (1968). Absorption of oleic and palmitic acids from emulsions and micellar solutions. J. clin. Invest., 47, 1015-1025.

Thompson, G. R. (1970). Vitamin D deficiency after gastrectomy. The Scientific Basis of Medicine. Annual reviews, 260-275.

Thompson, G. R., Lewis, B., and Booth, C. C. (1966a). Absorption of vitamin $\mathrm{D}_{3}-{ }^{-3} \mathrm{H}$ in control subjects and patients with irtestinal malabsorption. J. clin. Invest., 45, 94-102.

Thompson, G. R., Lewis, B., and Booth, C. C. (1966b). Vitamin D absorption after partial gastrectomy. Lancet, 1, 457-458.

Thompson, G. R., MacMahon, M. T., and Claes, P. (1970). Precipitation by Neomycin compounds of fatty acid and cholesterol from mixed micellar solutions. Europ. J. clin. Invest., 1, 40-47.

Thompson, G. R., Ockner, R. K., and Isselbacher, K. J. (1969). Effect of mixed micellar lipid on the absorption of cholesterol and vitamin $D_{3}$ into lymph. $J$. clin. Invest., 48, 87-95.

Thompson, W. G., and Thompson, G. R. (1969). Effect of cholestyramine on the absorption of vitamin $\mathrm{D}_{2}$ and calcium Gut, 10, 717-722.

Treadwell, C. R., and Vahouny, G. V. (1968). Cholesterol absorption, In Handbook of Physiology, section 6, vol. 3, pp. 1407-1438, edited by C. F. Code. American Physiological Society, Washington DC.

Whiteside, C. H., Harkins, R. W., Fluckiger, H. B., and Sarett, H. P. (1965). Utilization of fat-soluble vitamins by rats and chicks fed cholestyramine, a bile acid sequestrant. Amer. J. clin. Nutr., 16, 309-314. 